\title{
Response Surface Methodology for the Evaluation of Magnetite Partitioning Behavior in Polyethylene Glycol-Based Aqueous Biphasic System
}

\author{
Behnia Shahrokhi ${ }^{1}$ (D) $\cdot$ Mohsen Pirdashti ${ }^{1} \cdot$ Mozhgan Managhebi $^{2}$
}

Received: 28 May 2018/Accepted: 4 September 2019/Published online: 18 September 2019

(C) The Author(s) 2019

\begin{abstract}
Response surface methodology in the framework of central composite design has successfully applied to polyethylene glycol (PEG)-based aqueous two-phase system in order to evaluate its efficiency in extracting Fe from iron ores with respect to PEG molecular weight, PEG concentration and salt concentration factors. Furthermore, ANOVA and multiple regression analysis have provided a second-order polynomial equation that is highly capable of predicting the experimental results. The PEG molecular weight and weight percent of the salt in the feed had a major and minor effects on the iron ion partition coefficient, respectively.
\end{abstract}

Keywords Iron ion · Aqueous two-phase system · Response surface methodology · Polyethylene glycol ·

Zinc sulfate

\section{Introduction}

Iron is one of the most precious metals that can provide industrial and civil development due to its wide range of applications. For example, it can be employed in constructing and manufacture of machine parts and vehicles (Mazumdar 2001), building structures (Emsley 2011) and ship hulls (Townsin 2003). Also, iron is an imperative material for appliance and surgical equipment (Cornell and Schwertmann 2003). Furthermore, when it is used in its stainless formulation, it can be applied in electrical (Callister and Rethwisch 2011) and steel (Emsley 2011) industries. That is why iron production has been accelerated.

Mohsen Pirdashti

pirdashti@yahoo.com

Behnia Shahrokhi

behniashahrokhi@gmail.com

Mozhgan Managhebi

managhebio@hotmail.com

1 Chemical Engineering Department, Faculty of Engineering, Shomal University, PO Box 731, Amol, Mazandaran, Iran

2 Chemical Engineering Department, Faculty of Engineering, North Tehran Branch, Islamic Azad University, Tehran, Iran
One of the solutions of responding to the high level of worldwide demand for iron is its extraction from mines that are rich in it. In this respect, Iran is a great supplier, which has a large sector (12th place) of the world iron's reservoirs (http://www.iraninternationalmagazine.com/issue_74/texts p/iran's\%20mining\%20sector\%20statistics.htm). Specifically, Central Iran, mainly Bafq District, is so rich in iron (Sadeghi et al. 2013), and Chadormalu and Golgohar iron ore suppliers are the largest iron ore mines of Iran, which provide more than $80 \%$ of iron ore (Walter and Forciniti 1994).

One of these alternative treatments is using aqueous two-phase systems (ATPSs). ATPSs are liquid-liquid extraction systems that have been proposed for metal separation. ATPSs were first introduced in 1896 by Beijerinck, who reported that turbid solutions would form if aqueous gelatin and agar solutions or aqueous gelatin and starch solutions be mixed (Albertsson 1986). The unique feature of such system is that both phases are commonly consisted of over $80 \%$ water, but they are immiscible and their properties differ, significantly (Madeira et al. 2011, 2012, 2014). Consequently, many researchers have attempted to investigate metal partition coefficient and extraction yield of ATTPSs (Bulgariu and Bulgariu 2011, 2013; Bulgariu et al. 2007; Chen et al. 2009; da 
Rocha Patrício et al. 2011; de Lemos et al. 2013; Smolik et al. 2007).

Though ATPSs have demonstrated favorable characteristics, most industries and commercial applications have neglected its application. The principal underlying reason can regress back to our limited knowledge about the mechanism of metal and macromolecule equilibrium partitioning phenomenon. It, in turn, has restricted theoretical prediction of experimental trends. So that industries are not capable of pre-evaluation of the relevant industrial parameters and adjusting their production streams in accordance to this technique. However, this theoretical gap might be filled with appropriate theoretical modeling investigations.

Response surface methodology (RSM) has been used as a mathematical tool by many researchers to optimize and analyze effectiveness of several variables on partitioning of biomolecules in ATPSs (Alcântara et al. 2011; Aydoğan et al. 2011; Dembczyński et al. 2013; Silva et al. 2009), and RSM is a commonly utilized approach for generation of approximate models founded on experimental observations (El-Taweel and Gouda 2011) Also, Hill and Hunter (Hill and Hunter 1966) and Bezerra et al. (Bezerra et al. 2008) have published reviews about RSM and its application for optimization of analytical methods, respectively.

Though theoretical studies have been attempting to realize partitioning mechanisms of biomolecules in ATPS procedure, the findings are still insufficient and further investigations are essential. Moreover, to the best of our knowledge, no study has undertaken analysis and understanding of metal ions partitioning in ATPS process by the means of RSM. Therefore, this work aims to study partitioning of iron ions using an ATPS formed by a polyethylene glycol (PEG) (2000, 4000 and $6000 \mathrm{~g} \mathrm{~mol}^{-1}$ ), zinc sulfate and water, at $298 \mathrm{~K}$. Further, the impact of different parameters, such as molecular weight (MW), salt concentration and polymer concentration, is illustrated by RSM.

\section{Experiments}

\subsection{Materials}

Several PEG materials with average molecular weights of 2000, 4000 and $6000 \mathrm{~g} \mathrm{~mol}^{-1}$ and zinc sulfate (anhydrous GR $>99 \%$ for analysis) were obtained from Merck (Darmstadt, Germany). Hydrochloric acid (95-97\% $\mathrm{HCl}$; GR $>95.0 \%$ for analysis), $\mathrm{Na}_{2} \mathrm{CO}_{3}$ and $\mathrm{K}_{2} \mathrm{CO}_{3}$ were retrieved from Rankem (New Delhi, India), and potassium thiocyanate was purchased from Sigma-Aldrich, Germany. All throughout the experiments, deionized water was used for solution preparation. The other materials were of analytical grades.

\subsection{Apparatus and Procedure}

The effects of several experimental parameters on partition behavior of magnetite in ATPSs were investigated by first preparing to leachate iron from iron concentrate. In the next step, two aqueous phase systems of PEG and zinc sulfate salt in presence of Fe ion and potassium thiocyanate (da Rocha Patrício et al. 2011) were prepared as the extracting agents, according to the experimental design. It is noteworthy that in our previous work (Shahrokhi et al. 2017) we determined the two-phase region of this ATPS, in addition to the ranges of PEG and salt concentrations in that two-phase region. Then, Fe ion partition coefficient was calculated and the obtained data were implemented in RSM software to extract a RSM model. Finally, through the model, the relationships between input and output variables were identified. Figure 1 summarizes the flow diagram of the applied procedure, in this study.

\subsubsection{Leachate Iron from the Iron Concentrate}

Magnetite concentrate sample of $0.25 \mathrm{~g}$ was weighted and inserted in a platinum crucible. Then, sodium potassium carbonate was added as a mixture fusion and the mixture was fused in a muffle furnace, at $950{ }^{\circ} \mathrm{C}$ for about half an hour. After taking it out of the furnace and cooling it, the crucible was inserted in a glass beaker. Then, $\mathrm{HCl} 1: 1$ was added to the crucible. When all the sample was dissolved in acid, the crucible was removed and diluted in a $250-\mathrm{mL}$ volumetric flask. Flame atomic absorption spectrometer (FAAS) (Australia, VARIAN AA100) with $248.3 \mathrm{~nm}$ wavelength, $1.5 \mathrm{mg} \mathrm{L}^{-1}$ sensitivity check and air-acetylene flame flux of $1.5 \mathrm{~L} \mathrm{~min}^{-1}$ was employed to measure concentration of main metals in the obtained solution, which resulted in a 0.2 absorption peak, at $248.3 \mathrm{~nm}$. Table 1 reports concentration of the main metals in the final solution.

\subsubsection{Preparation of the Two-Phase System}

A solution containing 50\% w/w stock PEG solution, 30\% w/w zinc sulfate and potassium thiocyanate, as the extractor agent (da Rocha Patrício et al. 2011), was prepared. Then, iron ion solution of $30 \mathrm{mg} \mathrm{L}^{-1}$ concentration was poured in a graduated centrifuge tube and centrifuged (Thermo Scientific, Heraeus Megafuge 11R).

\subsubsection{Experimental and Optimization of Iron Extraction from Ore Leachate}

In this study, Design Expert 7 (Stat-Ease Inc., Minneapolis, $\mathrm{MN}$, USA) software was employed to carry out regression 
Fig. 1 Flow diagram of the procedure applied to analysis of iron partitioning

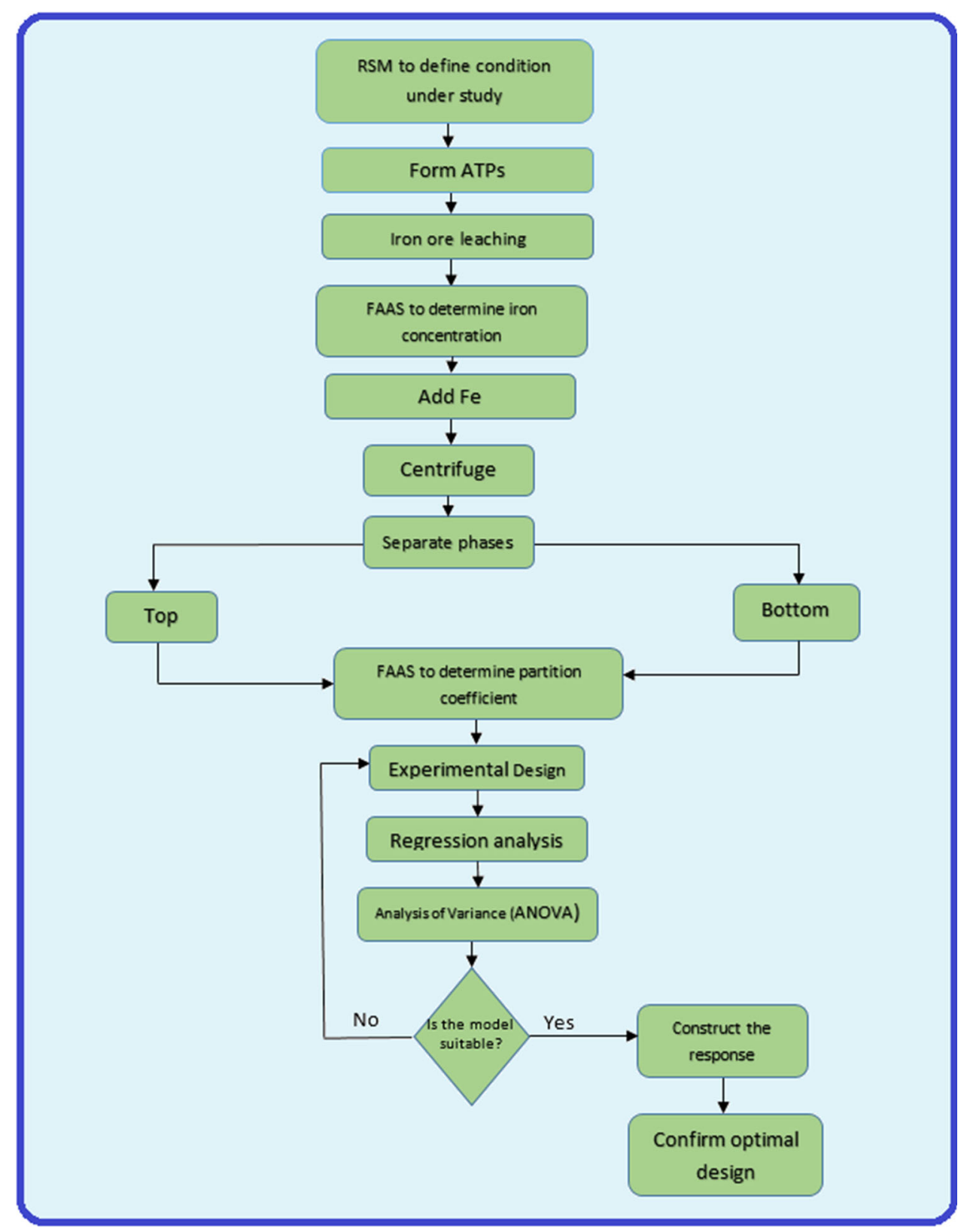

\begin{tabular}{llllllllll}
\hline Component & $\mathrm{Fe} \%$ & $\mathrm{FeO} \%$ & $\mathrm{Fe}_{2} \mathrm{O}_{3} \%$ & $\mathrm{Si}_{2} \mathrm{O} \%$ & $\mathrm{Al}_{2} \mathrm{O}_{3} \%$ & $\mathrm{MgO} \%$ & $\mathrm{~S} \%$ & $\mathrm{P} \%$ & L.o.I $^{\mathrm{a}}$ \\
\hline Sample & 67.47 & 22.45 & 71.52 & 1.51 & 0.77 & 5.18 & 0.10 & 0.029 & 1.35 \\
\hline
\end{tabular}

${ }^{\mathrm{a}}$ L.o.I loss on ignition

and graphical analysis of the generated data. Table 2 presents the factors and levels employed in this approach. Furthermore, one of the major responses, i.e., partition coefficient, was selected as the response. Then, in the second stage, RSM was used to investigate the impacts of three major factors including polymer concentration, salt concentration and polymer MW on the response. Based on this method, a quadratic model (Eq. 1) was utilized to describe each variable response:

$Y=\beta_{0}+\sum_{i=1}^{k} \beta_{i} x_{i}+\sum_{i=1}^{k} \beta_{i i} x_{i}^{2}+\sum_{i=1}^{k-1} \sum_{j=2}^{k} \beta_{i j} x_{i} x_{j}+\varepsilon$

In Eq. 1, $Y$ is the predicted response (i.e., Fe ion partition coefficient); $x_{i}$ and $x_{j}$ are input variables affecting the 
Table 2 Levels and factors regarding two-level fractional factorial study of iron ion partitioning

\begin{tabular}{lrlr}
\hline Factor & \multicolumn{3}{l}{ Range and level } \\
\cline { 2 - 4 } & -1 & 0 & +1 \\
\hline PEG MW & 2000 & 4000 & 6000 \\
Salt concentration & 15 & 20 & 25 \\
PEG concentration & 25 & 32.5 & 40 \\
\hline
\end{tabular}

response (the factors in Table 2); and $\mathrm{k}$ is the partition coefficient. As an outcome, squared effects are represented by $x_{i}^{2}, x_{j}^{2}$ to $x_{k}^{2}$ and mutual interactions between the case effects are concerned with $x_{i} x_{j^{-}}, x_{i} x_{k^{-}}$and $x_{j} x_{k^{-}}$-containing terms. Also, $\beta_{0}$ stands for the intercept, while $\beta i(i=1,2$, $\ldots, k), \beta i i(i=1,2, \ldots, k)$ and $\beta i j(i=1,2, \ldots, k ; j=1,2$, $\ldots, k)$ are the linear, squared and interaction effects coefficients, respectively. $\varepsilon$ refers to random error. (Aksu and Gönen 2006; Göksungur et al. 2005).

It should be noted that all experimental data were analyzed by analysis of variance (ANOVA) as embedded in Design Expert Software. Within this analysis tool, fitting quality of the model was confirmed through determining root-mean-squared deviation $\left(R^{2}\right)$. Moreover, the final subset of variables was chosen on the basis of the respective $p$ value at $95 \%$ level of confidence.

The related response, i.e., partition coefficient $K$, can be calculated as a function of equilibrium $\mathrm{Fe}$ ion concentration (the solute) in the two phases, following Eq. 2:

$K=\frac{[\mathrm{Fe} \text { concentration }]_{\text {top }}}{[\mathrm{Fe} \text { concentration }]_{\text {bottom }}}$

\section{Results and Discussion}

\subsection{Fitting the Model and Statistical Analysis}

ANOVA analysis gave significant terms of the model for each response while their significances were evaluated according to the calculated probability levels for them being below $5 \%$. Also, regression analysis $\left(R^{2}\right.$ and adjusted- $R^{2}$ determination coefficients) approved correlation of the results and their adequacies. The results of statistical analysis of the quadratic model (ANOVA) are summarized in Table 3. These results demonstrate statistical significance of this regression $(F=34.65, p<0.0001)$. Also, the obtained determination fitting value of $R^{2} \quad(=0.9303)$ implied that the model is successful in explaining $93.03 \%$ of the experimental variables. In addition, adjusted $R^{2}$ value of 0.9054 declared high significance of the generated model.
As the model was statistically verified, the regression equation was employed to partition $\mathrm{Fe}$ ion as a function of PEG and $\mathrm{ZnSO}_{4}$ concentrations and also PEG MW. Fitting of the experimental data and application of multiple regression analysis provided a second-order full polynomial equation, in the framework of CCD design. This acquired equation, which shows an empirical relationship between iron ion partition $(Y)$ and the independent variables, as shown in Eq. 3:

$$
\begin{aligned}
K= & +1.46665-0.015300 X_{1}-6.06000 E-003 X_{2} \\
& -3.35013 E-004 X_{3}+2.32500 E-006 X_{1} * X_{3} \\
& +0.000000180 X_{3}^{2}
\end{aligned}
$$

Here, as aforementioned, $K$ is the percentage of $\mathrm{Fe}$ ion partition coefficient, i.e., the response. In addition, $X_{1}, X_{2}$ and $X_{3}$ are polymer concentration, salt concentration and PEG MW values, respectively.

It can be observed that Fe partition coefficient would decrease upon MW increase. Meantime, changes in PEG concentration would result in increased volume of the upper phase with elevated PEG concentration. This volume change has negative impact on $\mathrm{Fe}$ ion partitioning since $\mathrm{K}$ equals to ratio of iron ion concentration in the upper phase to the lower phase concentration. As an outcome, it will decrease if PEG concentration increases. On the other hand, it was inferred from the results that $\mathrm{ZnSO}_{4}$ concentration poses the smallest impact on $\mathrm{Fe}$ ion partitioning, while higher $\mathrm{ZnSO}_{4}$ weight percent reduces $\mathrm{Fe}$ ion partition coefficient.

Findings revealed that increasing PEG MW would decrease $\mathrm{Fe}$ partition. The reason is attributed to more hydrophobicity of the polymer-rich phase, when PEG MW is higher. Intensified hydrophobicity can facilitate entrance of the complexes to the top phase. It means that if higher MW PEG polymers be used in the ATPS process, then improved partition of $\mathrm{Fe}$ ion (magnetite partition) can be guaranteed. This finding is also supported by other researches on ATPS application to gold (Zheng et al. 2015) and gallium (Chen et al. 2009) extraction.

Figures 2 and 3 display contour and 3D surface plots to elucidate the main and interactive effects of the independent variables on the dependent variable.

\subsection{Optimum Conditions and Model Verification}

Table 4 reports the optimum conditions for Fe ions partition, which are determined based on RSM.

Figure 4 shows $\mathrm{Fe}$ ion partition coefficient. In this figure, maximum $\mathrm{Fe}$ ion partition is marked with a triangle sign. 
Table 3 Analysis of variance (ANOVA) for response surface quadratic model

\begin{tabular}{llllrr}
\hline Source of variation & SS & $d f$ & Mean square & $F$ value & $p$ value \\
\hline Model & 0.31000 & 5 & 0.061 & 37.36 & $<0.0001$ \\
PEG MW & 0.02000 & 1 & 0.020 & 12.37 & 0.0034 \\
PEG concentration & 0.00918 & 1 & 0.00918 & 5.61 & 0.0328 \\
Salt concentration & 0.22000 & 1 & 0.22 & 136.87 & $<0.0001$ \\
PEG concentration * MW & 0.00973 & 1 & 0.00973 & 5.94 & 0.0287 \\
{$[\mathrm{MW}]^{2}$} & 0.04300 & 1 & 0.043 & 26.01 & 0.0002 \\
Residual & 0.02300 & 14 & 0.00163 & & \\
Lack of feed & 0.01600 & 9 & 0.00181 & 1.39 & 0.3763 \\
$R^{2}$ & 0.9303 & & & & \\
$R_{\text {adj }}^{2}$ & 0.90540 & & & &
\end{tabular}

\%CV 17.92
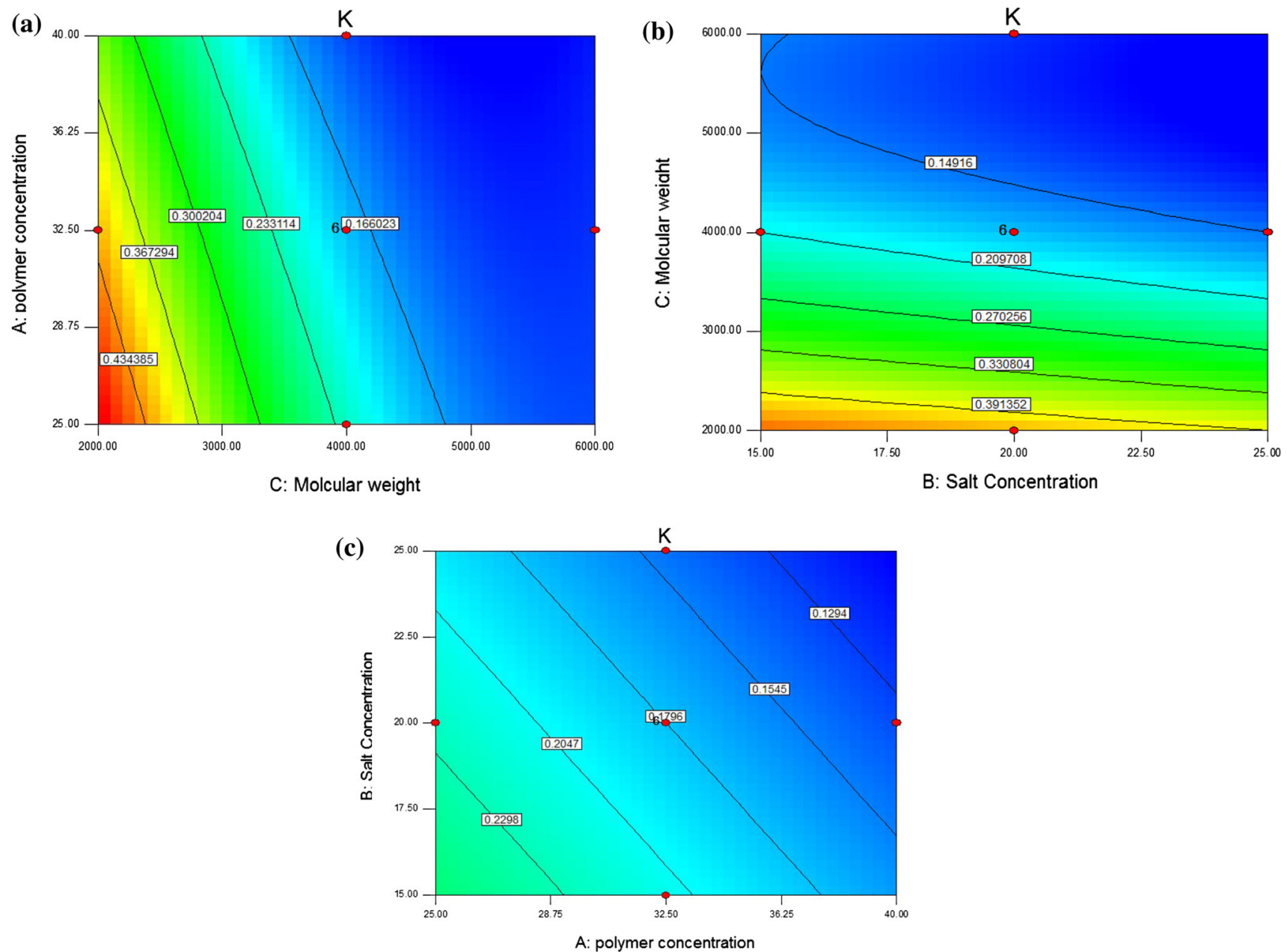

Fig. 2 Contour plot of iron ion partition: a polymer concentration and MW; b salt concentration and polymer MW; and $\mathbf{c}$ salt concentration and polymer concentration 

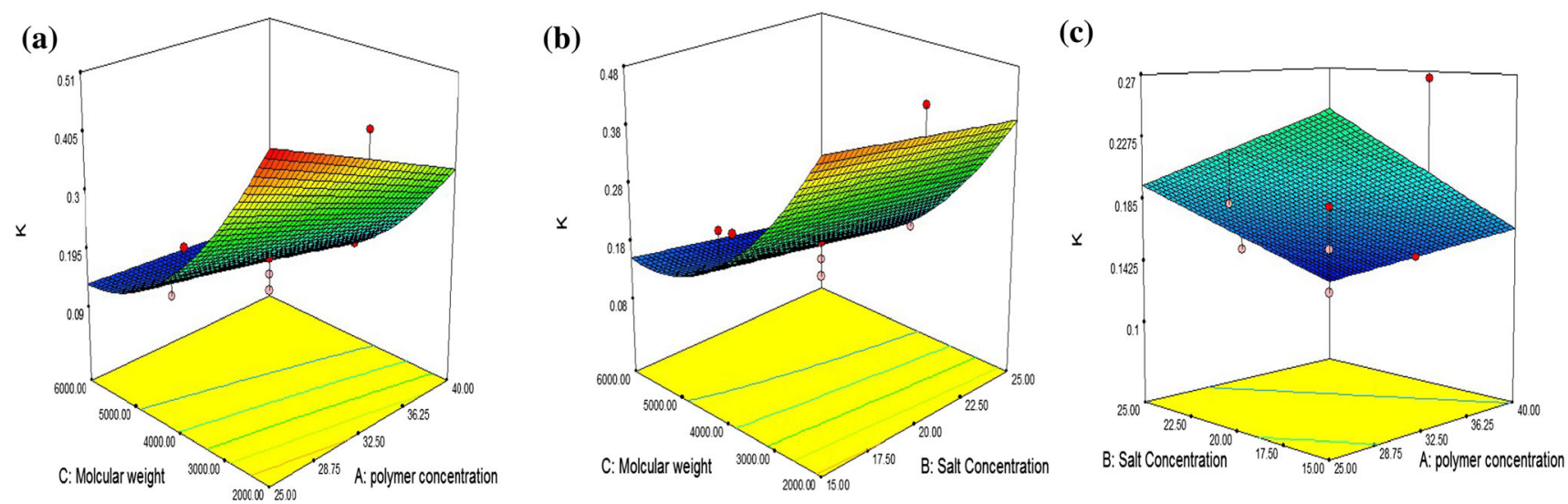

Fig. 3 Response surface plots for the effect of a polymer concentration and MW; $\mathbf{b}$ salt concentration and polymer MW; and $\mathbf{c}$ salt concentration and polymer concentration

Table 4 Optimum conditions for Fe partition

\begin{tabular}{llll}
\hline Polymer concentration & Salt concentration & MW & Desirability \\
\hline 26.50 & 16.00 & 2000 & 1 \\
\hline
\end{tabular}

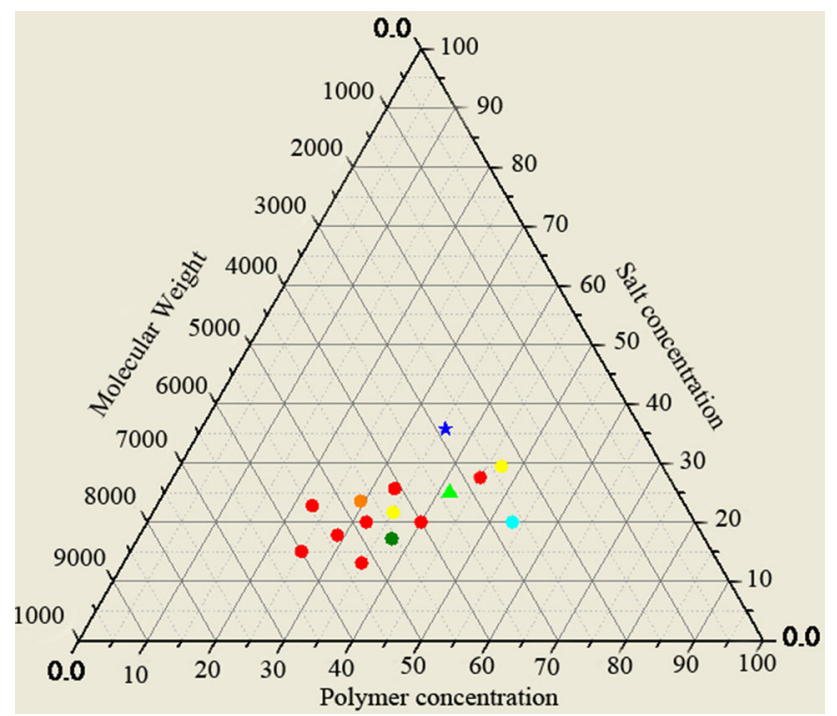

Fig. 4 Maximum partition coefficient of Fe ion in ATPS

\section{Conclusion}

Extensive use of iron in technology and industry has made it a very important metal in survival and improvement of modern life quality. Therefore, promotion of its extraction from iron ores is an essential objective. In this respect, response surface methodology was used to collect maximum experimental data for minimum number of experiments and evaluate effectiveness of different variables on separation of $\mathrm{Fe}$ through ATPS approach. In order to prepare the separation phases, zinc sulfate and polyethylene glycol were used. The modeling results verified that the applied ATPS method has the potency of extracting Fe ion and identified the impacts of PEG MW, salt concentration and PEG concentration on $\mathrm{Fe}$ ion partition among the two phases. According to the results, PEG MW can affect iron partitioning, noticeably, while its optimum value is $2000 \mathrm{~g} / \mathrm{mol}$. Meanwhile, it was revealed that higher PEG concentration poses unfavorable impacts on $\mathrm{Fe}$ partition.

Open Access This article is distributed under the terms of the Creative Commons Attribution 4.0 International License (http://creative commons.org/licenses/by/4.0/), which permits unrestricted use, distribution, and reproduction in any medium, provided you give appropriate credit to the original author(s) and the source, provide a link to the Creative Commons license, and indicate if changes were made.

\section{References}

Aksu Z, Gönen F (2006) Binary biosorption of phenol and chromium (VI) onto immobilized activated sludge in a packed bed: prediction of kinetic parameters and breakthrough curves. Sep Purif Technol 49(3):205-216

Albertsson P-A (1986) Partition of cell particles and macromolecules. In: Separation and purification of biomolecules, cell organelles, membranes, and cells in aqueous polymer two-phase systems and their use in biochemical analysis and biotechnology, 3rd edn. Wiley, New York

Alcântara LAP, Minim LA, Minim VPR, Bonomo RCF, Da Silva LHM, Da Silva MdCH (2011) Application of the response surface methodology for optimization of whey protein partitioning in PEG/phosphate aqueous two-phase system. J Chromatogr B 879(21):1881-1885

Aydoğan Ö, Bayraktar E, Mehmetoğlu Ü (2011) Aqueous two-phase extraction of lactic acid: optimization by response surface methodology. Sep Sci Technol 46(7):1164-1171

Bezerra MA, Santelli RE, Oliveira EP, Villar LS, Escaleira LA (2008) Response surface methodology (RSM) as a tool for optimization in analytical chemistry. Talanta 76(5):965-977 
Bulgariu L, Bulgariu D (2011) Extraction of gold (III) from chloride media in aqueous polyethylene glycol-based two-phase system. Sep Purif Technol 80(3):620-625

Bulgariu L, Bulgariu D (2013) Selective extraction of $\mathrm{Hg}($ II), Cd(II) and $\mathrm{Zn}$ (II) ions from aqueous media by a green chemistry procedure using aqueous two-phase systems. Sep Purif Technol 118:209-216

Bulgariu L, Bulgariu D, Sârghie I, Măluțan T (2007) Cd (II) extraction in PEG-based two-phase aqueous systems in the presence of iodide ions. Analysis of PEG-rich solid phases. Open Chem 5(1):291-302

Callister WD, Rethwisch DG (2011) Materials science engineering. Wiley, New York

Chen Y, Liu X, Lu Y, Zhang X (2009) Investigation of gallium partitioning behavior in aqueous two-phase systems containing polyethylene glycol and ammonium sulfate. J Chem Eng Data 54(7):2002-2004

Cornell RM, Schwertmann U (2003) The iron oxides: structure, properties, reactions, occurrences and uses. Wiley, New York

da Rocha Patrício P, Mesquita MC, da Silva LHM, da Silva MCH (2011) Application of aqueous two-phase systems for the development of a new method of cobalt(II), iron(III) and nickel(II) extraction: a green chemistry approach. J Hazard Mater 193:311-318

de Lemos LR, Campos RA, Rodrigues GD, da Silva LHM, da Silva MCH (2013) Green separation of copper and zinc using triblock copolymer aqueous two-phase systems. Sep Purif Technol 115:107-113

Dembczyński R, Białas W, Jankowski T (2013) Partitioning of lysozyme in aqueous two-phase systems containing ethylene oxide-propylene oxide copolymer and potassium phosphates. Food Bioprod Process 91(3):292-302

El-Taweel TA, Gouda S (2011) Performance analysis of wire electrochemical turning process-RSM approach. Int $\mathbf{J}$ Adv Manuf Technol 53(1-4):181-190

Emsley J (2011) Nature's building blocks: an AZ guide to the elements. Oxford University Press, Oxford

Göksungur Y, Üren S, Güvenç U (2005) Biosorption of cadmium and lead ions by ethanol treated waste baker's yeast biomass. Bioresour Technol 96(1):103-109

Hill WJ, Hunter WG (1966) A review of response surface methodology: a literature survey. Technometrics 8(4):571-590
Madeira PP, Reis CA, Rodrigues AE, Mikheeva LM, Chait A, Zaslavsky BY (2011) Solvent properties governing protein partitioning in polymer/polymer aqueous two-phase systems. J Chromatogr A 1218(10):1379-1384

Madeira PP, Bessa A, Álvares-Ribeiro L, Aires-Barros MR, Reis CA, Rodrigues AE, Zaslavsky BY (2012) Salt effects on solvent features of coexisting phases in aqueous polymer/polymer twophase systems. J Chromatogr A 1229:38-47

Madeira PP, Bessa A, Álvares-Ribeiro L, Raquel Aires-Barros M, Rodrigues AE, Uversky VN, Zaslavsky BY (2014) Amino acid/ water interactions study: a new amino acid scale. J Biomol Struct Dyn 32(6):959-968

Mazumdar S (2001) Composites manufacturing: materials, product and process engineering. CRC Press, Boca Raton

Sadeghi B, Khalajmasoumi M, Afzal P, Moarefvand P, Yasrebi AB, Wetherelt A, Foster P, Ziazarifi A (2013) Using ETM + and ASTER sensors to identify iron occurrences in the Esfordi 1: 100,000 mapping sheet of Central Iran. J Afr Earth Sci 85:103-114

Shahrokhi B, Pirdashti M, Mobalegholeslam P, Rostami AA (2017) Liquid-liquid equilibrium and physical properties of aqueous mixtures of PEG1500 with zinc sulfate at different $\mathrm{pH}$ : experiment, correlation and thermodynamic modeling. Chem Eng Data 62(3):1106-1118

Silva C, Bovarotti E, Rodrigues M, Hokka C, Barboza M (2009) Evaluation of the effects of the parameters involved in the purification of clavulanic acid from fermentation broth by aqueous two-phase systems. Bioprocess Biosyst Eng 32(5):625-632

Smolik M, Jakóbik-Kolon A, Porański M (2007) Extraction of zirconium and hafnium in polyethylene glycol-based aqueous biphasic system. Sep Sci Technol 42(8):1831-1841

Townsin R (2003) The ship hull fouling penalty. Biofouling 19(S1):9-15

Walter H, Forciniti D (1994) Cross-partitioning: determination of isoelectric point by partitioning. Methods Enzymol 228:223-233

Zheng Y, Tong Y, Wang S, Zhang H, Yang Y (2015) Mechanism of gold(III) extraction using a novel ionic liquid-based aqueous two-phase system without additional extractants. Sep Purif Technol 154:123-127 